\title{
Automated High-Speed Analysis of Selected Organic Compounds in Urban Air by On-Line Isotopic Dilution Cryofocusing Gas Chromatography / Mass Spectrometry
}

\author{
E. Davoli, L. Cappellini, M. Moggi, and R. Fanelli \\ Istituto di Ricerche Farmacologiche "Mario Negri", 20157 Milano, Italy
}

\begin{abstract}
An automated environmental air monitor has been developed to measure selected organic compounds in urban air. The instrument is based on a cryofocusing-thermal desorption gas chromatographic mass spectrometry technique where the mass spectrometer is a slightly modified residual gas analyzer (RGA). The RGA was chosen as a detector because the whole system must be robust for long periods, with 24-h continuous air monitoring. RGA are extremely simple and seemed the most reliable mass spectrometers for this purpose. Moreover, because they have no physically limited ion source, contamination is considerably reduced, so maintenance intervals are longer.

The gas chromatograph is equipped with a computer-controlled six-way sampling valve, with a $100-\mathrm{mL}$ sampling loop and thermal desorption cold trap injector. Environmental air is enriched with an isotopically labeled internal standard in the sampling line. This internal standard is added with a validated, custom-made, permeation tube device. The "on-line" internal standard provides for high quality quantitative data because all variations in instrument sensitivity in cryofocusing or in thermal desorption efficiency are taken into account. High repetition rates (down to $5 \mathrm{~min}$ for a full analytical cycle) are obtained with the use of an isothermal gas chromatography program, microbore capillary column, and environmental air sampling during the gas chromatography run. (/ Am Soc Mass Spectrom 1994, 5, 1001-1007)
\end{abstract}

$\mathrm{H}$ eightened awareness of chemical pollutants in the atmosphere has led to increasing interest in analytical techniques for monitoring volatile organic compounds (VOC) in urban air. VOC monitoring is therefore part of the quest for more accurate characterization of environmental air, and is necessary to better understand the different sources of pollutants and their atmospheric chemistry and to provide a more significant scientific basis for assessment of exposure [1, 2] and risk analysis [3].

Median levels of nonmethane hydrocarbons in U.S. cities have been closely studied, and median values of the 25 most abundant volatile organic compounds are in the range of $4.7-45 \mathrm{ppb}$ [4]. This is in agreement with the limited data currently available for Italian cities [5]. Analysis of these traces of organic compounds in the air is a common problem that requires high sensitivity and high specificity. The most widely used methods involve two steps: sample collection and detection. Samples are collected by filling passivated canisters or sample bags or drawing a known volume

Address reprint requests to Dr. E. Davoli, Environmental Pharmaculogy and Toxicology Laboratory, Istituto di Ricerche Farmacologiche "Mario Negri", Via Eritrea 62, 20157 Milano, Italy. of air through a solid sorbent, like activated charcoal or porous polymer, or, if the sample is reactive, bubbling the air in an impinger [6]. Subsequent analysis is by high-performance liquid chromatography (HPLC), gas chromatography (GC), or gas chromatography/ mass spectrometry (GC/MS). When capillary $G C$ is used, air samples are passed through a cryogenically cooled trap to concentrate analytes and then heated fast enough to desorb the analytes in a narrow band that is compatible with high-resolution capillary columns [7-13]. Some direct analysis is possible in the parts per billion range by taking advantage of the selectivity of mass spectrometry and of the sensitivity and selectivity of atmospheric pressure ionization (API) with a glow discharge ionization source [14] or with a corona discharge ionization source with tandem mass spectrometry [15].

The internal standard is generally added after sampling by spiking the sorbent material [10] before solvent extraction or thermal desorption. Collection efficiencies and sampling losses are taken into account by calculating a correction factor from analysis of samples with known concentrations [7]. Competitive effects between different compounds in the adsorbent material are realistic during emissions and environmental air 
monitoring, and these cross-interactions modify the breakthrough volumes of single compounds [16]. Although Langmuir-derived equations have been described [17] to predict this breakthrough, a reliable internal standard is still desirable.

Our laboratory has been interested in the development of a method based on mass spectrometry [18] for monitoring urban air. We recently proposed a technique, which is based on stable isotope permeation tubes, that allows on-line addition of the internal standard to the air sample stream. We therefore chose mass spectrometry as the detection system because we wanted to use a stable isotope-labeled internal standard on-line to benefit from the widely recognized advantages of the stable isotope dilution technique [19].

To plot a detailed as possible picture of pollution patterns induced by traffic in rush and nonrush hours, we were also looking for a high repetition rate. Benzene and toluene were chosen as hydrocarbons representative of VOC urban pollutants because of their toxicological relevance $[20,21]$ and the abundance of toluene in urban air [4].

In addition to industrial emissions, another significant aspect of these two compounds is that their concentrations in urban air are mainly (up to $85 \%$ ) due to emissions from vehicle exhaust tailpipes $[22,23]$ and other automobile-related activities [24, 25], so their variations in air should be related primarily to the traffic intensity.

\section{Experimental}

\section{Materials}

Benzene and toluene were analytical grade and were obtained from Carlo Erba Reagenti (Milano, Italy). Benzene- $d_{6}$ was obtained from Aldrich Chemical Co. (Milwaukee, WI) and had a minimum isotopic purity of 99.96 at. \% of deuterium.

\section{Mass Spectrometry}

The mass spectrometer was a RIAL QM 130 CS quadrupole residual gas analyzer (RGA) (RIAL Vacuurn S.p.A., Parma, Italy). This quadrupole is a commercially available 130-u range instrument that has cylindrical $125-\mathrm{mm}$ rods, a $6.35-\mathrm{mm}$ radius, and is equipped with an electron multiplier and a dualfilament open-geometry ion source. The pumping systein comprises a two-stage mechanical pump $\left(4 \mathrm{ml}^{3} / \mathrm{h}\right)$ and an air-cooled turbomolecular pump $(80 \mathrm{~L} / \mathrm{min})$.

Instrument control and data acquisition were originally done with a IBM compatible, MS-DOS computer, through a serial RS232 interface connected with the RGA Z80 microcomputer board. However the data acquisition system, which was designed for RGA operations with long integration time and slow data transfer, was not suitable for GC/MS analysis and now has been completely replaced by a commercially available
Vector One (Teknivent Corp., St. Louis, MO) data system. The electrometer has been modified to reduce the integration time to values compatible with GC-MS analysis (at highest gain the maximum integration time has been reduced to less than $1 \mathrm{~ms}$ ). RGA control is based on mass spectrometer control (MSC) resident software (TSR), which was developed in this laboratory, that sets and monitors RGA operational parameters like filament current, electron multiplier voltage, electrometer gain, and ion lens voltages. The MSC communicates with the mass spectrometer through the PC RS232 COM2 serial port with the original Z80 microcomputer board. Because no conflicts were observed between MSC and Vector One software, it was possible to load Vector One software after the MSC TSR program so that we could change instrumental parameters during calibration and data acquisition.

Interference studies have been performed with a HP-5971 (Hewlett-Packard, Palo Alto, CA) MSD commercial GC/MS instrument outfitted with the entire sampling line described in the Sampling Line section. The MSD was tuned in the 45-500-u range with the Hewlett-Packard standard autotune facility with no further optimization. The start of injection corresponds to the instant the cold trap starts to heat. The filament was turned on with zero time delay. The electron energy was $70 \mathrm{eV}$ and only positive ions were monitored.

\section{Gas Chromatography}

The gas chromatograph was a DANI (DANI S.p.A., Monza, Italy) 86.10 equipped with a split-splitless injector and a DANI VU65 six-way computer-controlled valve. The oven temperature was $120{ }^{\circ} \mathrm{C}$ isothermal. The column was fused silica $(10-\mathrm{m}$ CP Sil 5 $\mathrm{CB}, 150-\mu \mathrm{m}$ i.d., $2-\mu \mathrm{m}$ film thickness; Chrompack International BV, Middelburg, The Netherlands) connected directly to the RGA without modification of the open ion source. To enhance sensitivity the GC effluent was carried just in front of the open mesh ion source with $0.5-\mathrm{mm}$ i.d., uncoated deactivated fused silica tubing. The 13-cm-long GC/MS transfer line was built with standard ultra-high-vacuum components and Swagelock fittings (Swagelock Corp., Solon, $\mathrm{OH}$ ), and was thermostated up to $160^{\circ} \mathrm{C}$. The carrier gas was nitrogen, with a head pressure of 0.6 bar.

\section{Sampling Line}

Figure 1 shows the overall scheme of the instrument. Urban air was collected close to the sidewalk in front of the Mario Negri Institute with 50-m, 1-cm-i.d. nylon tubing. Air samples were withdrawn with a membrane pump and the effluent was connected to a flowmeter with a built-in needle valve that set the sampling flow to a known velocity. This sampling line was fitted with a permeation tube device to deliver a known amount of deuterated internal standard (benzene- $d_{6}$ ) in the stream of urban air sample. The permeation tube de- 


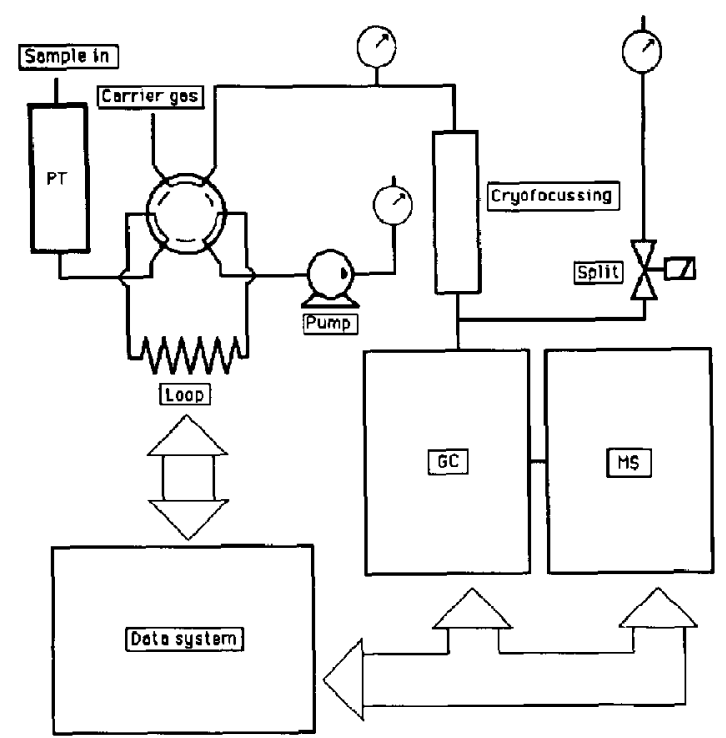

Figure 1. Schematic setup of the instrument used for this work.

vice was custom-made and is a simple thermostated cylindrical glass chamber with a permeation tube inside [25]. Permeation tubes are built in this laboratory with $3.175-\times 1.5-\times 35-\mathrm{mm}$ (o.d. $\times$ i.d. $\times$ length) poly(tetrafluoroethylene) (PTFE) tubing (Chrompack BV) capped with polished stainless steel rods (2-mm i.d. $\times 10-\mathrm{mm}$ length) and Swagelock caps with PTFE ferrules and filled with benzene- $t_{6}$. A silanized glass wool filter and a $0.2-\mu \mathrm{m}$ pore size, $5.3-\mathrm{cm}^{2}$ filtration area, cellulose acetate membrane filter were mounted in the line and replaced every $48 \mathrm{~h}$ of sampling. Automated on-line air analysis was done with a computercontrolled pneumatic six-way valve equipped with a $100-\mathrm{cm}^{3}$ stainless steel loop.

This air sample, enriched with the internal standard, is cryofocused in a thermal desorption cold trap injector (Chrompack BV) before entering the GC column. A summary of time events is shown in Figure 2. This table was used for all the experiments described herein. Alterations of the cycle to 5 - or 14-min repetition rates were obtained by changing the intercycle period, that is, the period that goes from 2 to $4 \mathrm{~min}$ in Figure 2. In this way no variations in sample size were introduced.

It is important to note that the GC column was connected to the cold trap with a split valve. During the cryofocusing stage, the split valve was open, which split the air out of the GC column. We made no further attempt with other switching valves to avoid the entrance of air to the chromatographic column during the trapping period.

\section{Quantitative Analysis}

Full-scan mass spectra of benzene, benzene- $d_{6,}$ and toluene were acquired with 1-s scans (1-130-u scans)

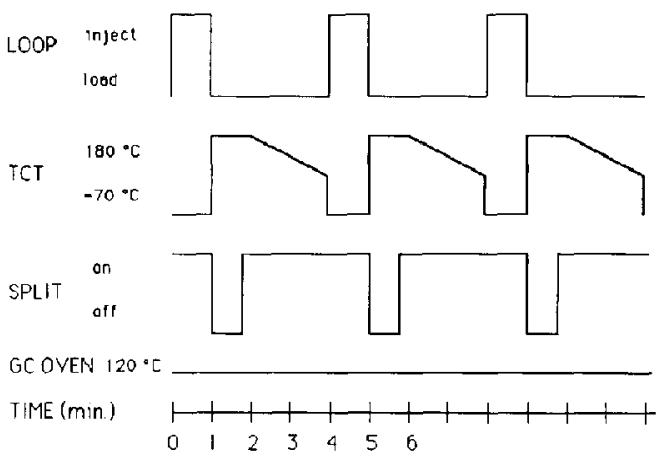

Figure 2. Time events table during a continuous air analysis with 5 -min repetition rates.

and were comparable with the NBS/Wiley reference library [26] (except deuterated benzene, which is not listed in the version we have). A calibration curve of benzene-benzene- $d_{6}$ and toluene-benzene- $d_{6}$ was prepared, with splitless injections of $1-\mu \mathrm{L}$ solutions that contained $10 \mathrm{ng} / \mu \mathrm{L}$ of internal standard and benzene and toluene in the range $50-5000 \mathrm{pg} / \mu \mathrm{L}$ in methanol. Mass spectrometry conditions were unmodified from the conditions used for on-line analysis. A selected ion monitoring program was used with 80-ms monitoring of $m / z 78,84$, and 91 (for benzene, benzene- $d_{6}$, and toluene, respectively). This calibration curve can be expressed as

$$
R=y=a+b x
$$

where $R$ is the chromatographic peak area ratio (benzene-benzene- $d_{6}$ ) and $x$ is the ratio of the amount (nanograms) injected (benzene-benzene- $d_{6}$ ). For the on-line analysis $x$ can be expressed as

$$
x=Q_{\text {benzene }} / Q_{\text {standard }}
$$

where $Q_{\text {benzenc }}$ is the amount (nanograms) of benzene in the sampled air volume and $Q_{\text {standard }}$ is the amount (nanograms) of internal standard in the sampled air volume.

Under the foregoing experimental conditions $Q_{\text {standard }}$ is calculated as

$$
Q_{\text {standard }}=\frac{P V}{F}
$$

where $P$ is the permeation rate of deuterated benzene (nanograms per minute), $F$ is the sampling flow rate (liters per minute), and $V$ is the sample volume (liters). Quantitation during on-line analysis was therefore obtained from eqs $1-3$ :

$$
\begin{aligned}
& Q_{\text {benzene }}=\frac{R-a}{b} \frac{P V}{F} \\
& C_{\text {benzene }}=\frac{Q_{\text {benzcne }}}{V}=\frac{R-a}{b} \frac{P}{F}
\end{aligned}
$$


where $C_{\text {benzene }}$ is the air sample concentration of benzene (nanograms per liter).

Permeation rate $P$ is experimentally calculated gravimetrically for each individual tube. The tube is kept in a ventilated oven at the same temperature as in the permeation tube device $\left(50{ }^{\circ} \mathrm{C}\right)$ for a period long enough (saturation stage) to reach $99 \%$ of its $P$ asymptotic value (steady state stage). During the saturation stage, permeation is not effectively controlled and therefore is not useful for producing a calibration standard [27]. Permeation rate is, in fact, represented by the slope of the time weight loss curve, expressed in nanograms per minute [28]. The experimental $P$ value is controlled with theoretical calculations $[18,27,28]$ to confirm diffusion rather than any gas leakage through seals, pores, or cracks.

Toluene concentrations were obtained with the same procedure by substituting the corresponding toluene quantities in eqs 1 and 2 and by using benzene- $d_{6}$ as the internal standard.

\section{Results}

Typical calibration curves obtained with splitless injections of methanolic solutions that contained various amounts of benzene and toluene and constant amount of benzene- $d_{6}(10 \mathrm{ng} / \mu \mathrm{L})$ are shown in Figure 3 . Calibration curves were obtained by plotting the ratio of the chromatographic peak area of the analyte ion to that for the internal standard (benzene- $d_{6}$ ) versus the mass of injected analyte. Linearity was good in the range of $50-5000 \mathrm{pg}$ that was injected splitless for both compounds; the coefficient of correlation was $>0.995$. The numerical constants $a$ and $b$ of the obtained calibration curve were used in eqs 13 for automatic quantitative analysis calculations.
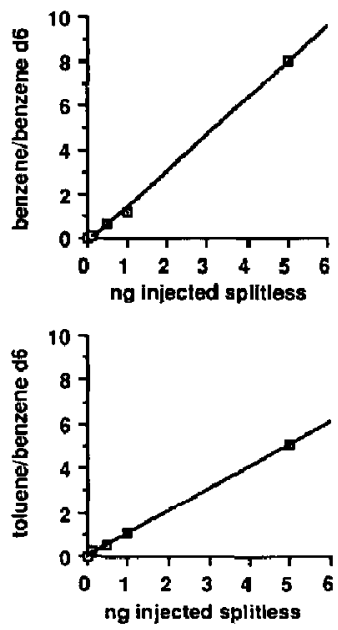

Figure 3. Calibration curves for quantitative analysis of benzene and toluene. The range was $50-5000 \mathrm{pg}$ injected splitless for both compounds ( $r \geq 0.995$ for benzene and toluene).
On-line internal standard measurements-expressed as area counts of the benzene- $d_{6}$ chromatographic peak-showed a highly precise instrumental response $[3637 \pm 3.06 \%$, mean \pm relative standard deviation (RSD)] throughout the experiments. This result corresponded to air concentrations of $266 \mu \mathrm{g} / \mathrm{m}^{3}$ for the permeation tube used during this experiment, with an air sample volume $V=0.1 \mathrm{~L}$ and a sampling flow $F=0.5 \mathrm{~L} / \mathrm{min}$. Air volumes larger than $0.1 \mathrm{~L}$ were not reliable because we observed clogging because of water freezing in the cold trap; with smaller samples this never happened. Ice formation was readily detectable with the instrumental settings because the internal standard area was not proportional to the amount of air measured or was not constant in time.

A 4-h segment of a typical chromatogram obtained under the experimental conditions described is shown in Figure 4. During this period the benzene- $d_{6}$ peak area was $2.095 \times 10^{5} \pm 1.7 \%$ (mean \pm RSD). Chromatographic resolution and peak shape were good even when the oven temperature was isothermal (Figure 5), which shows that thermal desorption of the analytes occurs in a sufficiently short time. No major interference peaks were observed in the analyte or in the correct internal standard time window.

Typically variations in retention time were very low. For example, for the chromatogram in Figure 4 , which had a 4-h acquisition with 5-min cycles, the benzene chromatographic peaks eluted every $5.0 \pm$ $0.25 \%$ min (mean \pm RSD). As can be seen in Figure 5a, no chromatographic peaks at $m / z=78$ were seen except for the two benzene injections at 31.2 and 36.2 min. At $m / z 91$ two peaks were observed. To prove the identity of these peaks and to identify other possible contaminants that might show under these experimental conditions, a full scan set of experiments was set up, but the sensitivity in the full scan mode was barely sufficient to identify the $266-\mu \mathrm{g} / \mathrm{m}^{3}$ benzene- $d_{6}$
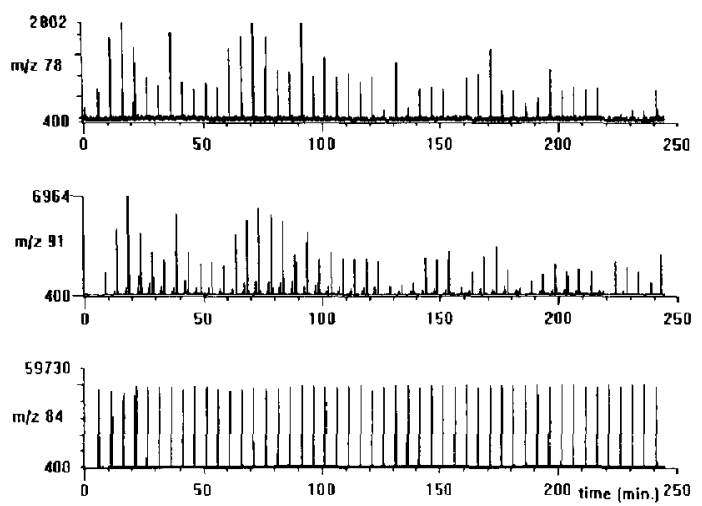

Figure 4. Initial part of the selected ion monitoring chromatogram obtained during on-line measurements of benzene $(m / z 78)$ and toluene $(m / z 91)$ in urban air. The lower trace is the internal standard, benzene- $d_{6}(m / z$ 84), added to the air sample stream with the permeation device described in the text. 

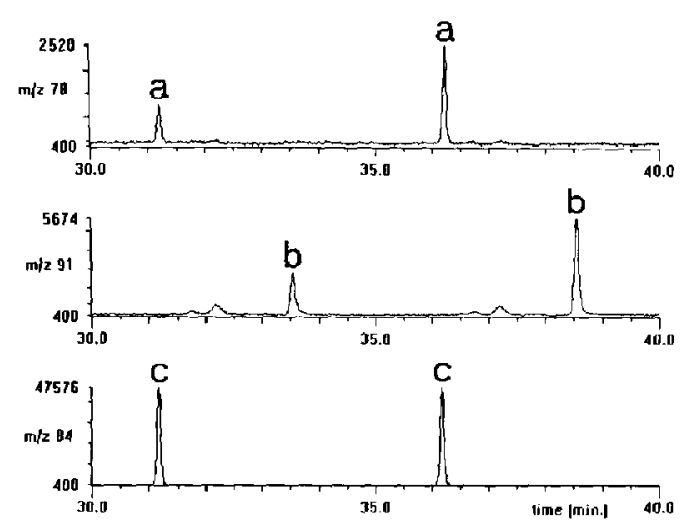

Figure 5. Expanded view of the selected ion monitoring chromatogram of Figure 4. Peaks are (a) benzene, (b) toluene, and (c) the internal standard benzene- $d_{6}$. The internal standard was 26.6 $\mu \mathrm{g} / \mathrm{m}^{3}$. Chromatographic resolution was good even when the GC oven was kept isothermally at $120{ }^{\circ} \mathrm{C}$ to speed up the analytical cycle. No major interference peaks were seen.

internal standard peak. Results from the sampling line installed on a Hewlett-Packard MSD mass spectrometer under the same experimental conditions showed no large coeluting interference peaks. In Figure $6 \mathrm{a}$ a total ion chromatogram, which acquires the full scan in the
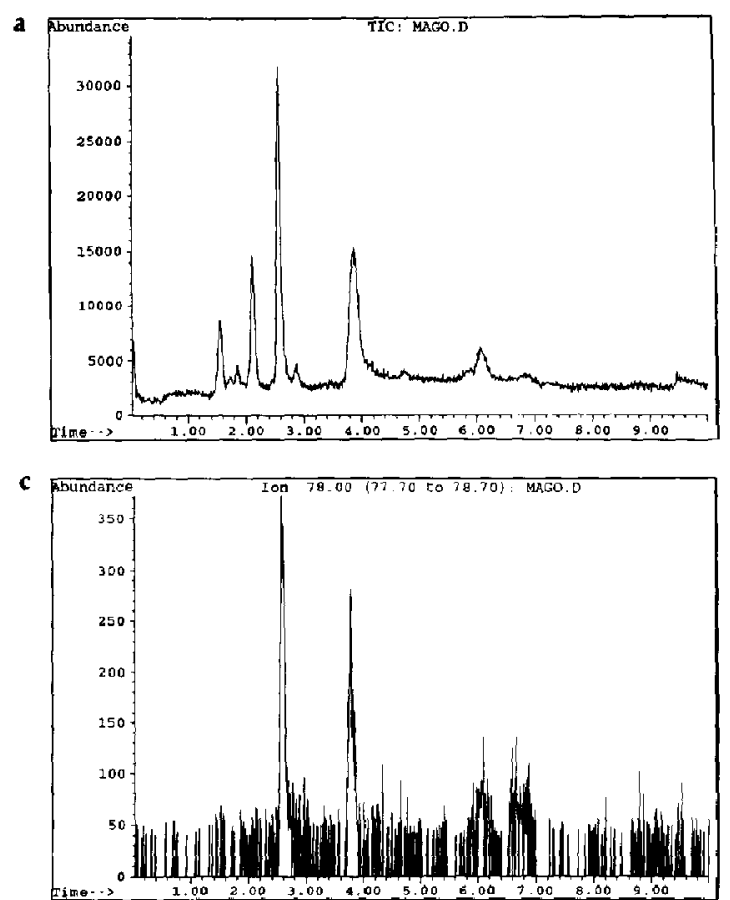

range $45-500 \mathrm{u}$, is shown, whereas in Figure $6 \mathrm{~b}-\mathrm{d}$ the reconstructed ion chromatograms of $m / z$ 84, 78, and 91 are, respectively, plotted. The peak that elutes at $2.57 \mathrm{~min}$ is identified as deuterated benzene $(\mathrm{m} / \mathrm{z} 84)$, which is the major peak in the total ion current, and benzene ( $\mathrm{m} / z$ 78 at $2.59 \mathrm{~min}$ ). Toluene elutes at 3.87 $\min (m / z 91)$, whereas peaks that elute at 5.91, 6.12 (poorly resolved), and $6.88 \mathrm{~min}$ are identified as the three xylene isomers.

Benzene and toluene peaks also have been identified on the MSD mass spectrometer with replicate injections of pure standards solutions and air samples via a comparison of ion relative intensities at $m / z 77$ over 78 for benzene and ions at $m / z 92$ over 91 for toluene. The standard benzene ion intensity ratio was $0.292 \pm 0.009$, whereas airborne benzene was $0.272 \pm$ 0.021 ; the toluene standard ratio was $0.544 \pm 0.012$, whereas airborne toluene was $0.576 \pm 0.027$ (mean \pm SD). Results from a Student's $t$ test confirmed no significant differences for the two benzene and toluene groups ( $p=0.203$ and 0.248 for the benzene standard versus airborne benzene and for the toluene standard versus airborne toluene, respectively).

As mentioned before no attempt was made, except to open the split valve, to prevent air entrance into the column during the trapping period. Air could therefore enter the column during the 1-min trapping time,
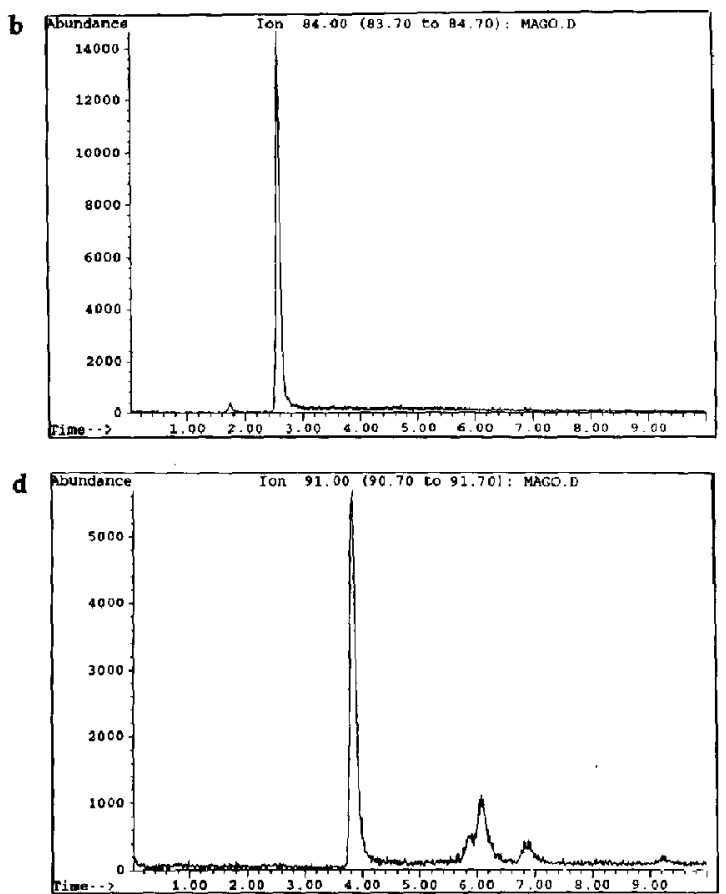

Figure 6. (a) Total ion current chromatogram obtained by sampling air with the line and the sampling cycle described in the text via a Hewlett-Packard 5971 MSD commercial quadrupole. This total ion current chromatogram was obtained in full scan mode, scanning from $m / z 45$ to 200 . The reconstructed ion chromatogram for the ions of (b) benzene- $d_{6}(m / z 84)$, (c) benzene $(m / z 78)$, and (d) toluene $(m / z 91)$ that are monitored with the RGA quadrupole during the environmental air monitoring experiments also are reported. Note that there are no major interferences in the full scan chromatogram or in the reconstructed ion chromatogram. Benzene elutes at 2.59 min and toluene elutes at $3.87 \mathrm{~min}$. 


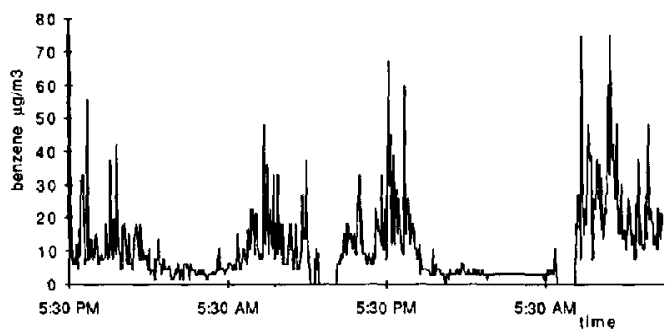

Figure 7. Results of a 48-h benzene monitoring experiment in urban air with a 5-min full analytical cycle. The concentrations were highest during the rush hours.

and the only limitation was the low gas flow conductance of the $10-\mathrm{m}, 150-\mu \mathrm{m}$ i.d. capillary column compared to the split line (all $1.587-\mathrm{mm}$ stainless steel tubing). During this period the overhead pressure was limited to ambient pressure because the split valve was open. No alterations in column performance were observed under these operating conditions.

Figure 7 shows the benzene concentrations in urban air for 48-h rontinunus sampling. This experiment was performed with the time events table of Figure 2 with one full analytical cycle every $5 \mathrm{~min}$. The major problem during this experiment was liquid nitrogen consumption: the tank we had available had a 20-L capacity and lasted for only $17 \mathrm{~h}$. Figure 8 shows the results of a 5-day experiment that monitored benzene and toluene $24 \mathrm{~h}$ per day. Here the analytical cycle was reduced to $14 \mathrm{~min}$ for practical reasons because liquid nitrogen refills were necessary every $48 \mathrm{~h}$. During this experiment no significant variation in the benzene- $d_{b}$ peak area was observed. The high concentrations of toluene observed on January 26 and 27 are because of weather conditions. A strong thermal inversion with high atmospheric stability occurred the night of January 26 and this was responsible for the increase in pollution in the city air. ${ }^{1}$ In Figure 9 carbon monoxide concentrations from a Milan district monitoring station a few kilometers from our sampling point are reported for the week that includes these days (data are given as hourly averages). Carbon monoxide is used as a surrogate for motor vehicle emissions studies (see, for example, ref 23) because the vast majority of $\mathrm{CO}$ comes from motor vehicles. Therefore the concentration of $\mathrm{CO}$ should track benzene and toluene concentrations. Note that a large peak in $\mathrm{CO}$ air concentrations is observed on the nights of January 26 and 29, in good agreement with our benzene and toluene trend.

\footnotetext{
${ }^{1}$ Meteonological data as well as carbon monoxide air pollution data are from the Atmospheric Physics Department of the $4^{\circ}$ Unità Operativa Fisica e Tutela dell'Ambiente, Presidio Multizonale Igiene e Prevenzione di Milano. U.S.S.L. 75/III, and are relevant to the "AGRATE" monitoring station that is the closest in Milan to the Mario Negri Institute.
}

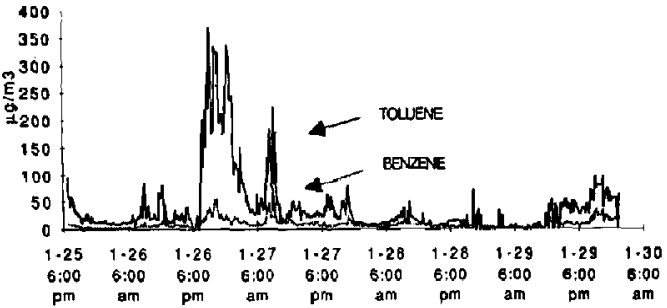

Figure 8. Results of a 5-day benzene and toluene monitoring experiment in urban air with a 14-min full analytical cycle. The highest concentrations each day wore obscrved during the rush hours. The differences on different days are probably due to weather conditions.

\section{Discussion}

The monitoring system described here is the first application, to our knowledge, that takes advantage of an "on-line" isotopic dilution technique [18, 29, 30]. Isotopic dilution was developed several years ago (31) and is still widely used in several fields-especially for quantitative analysis because of its high intrinsic accuracy. The use of an on-line isotopic dilution technique for air monitoring not only gives the accuracy of isotopic dilution, but also provides a continuous check of the efficiency of the cold trap. The stability of the internal standard chromatographic peak reflects the well known steadiness of the permeation tube emission as well as the overall stability of the system that begins with the cryofocusing efficiency to the thermal desorption and finally to the mass spectrometer response.

Variations in permeation rate due to humidity are theoretically possible when the permeant substance reacts with water. For example, $\mathrm{NO}_{2}$ forms $\mathrm{INO}_{2}$ and $\mathrm{HNO}_{3}$ in the membrane in the presence of humidity; therefore $\mathrm{NO}_{2}$ permeation rate disproportionates, with unpredictable ratios, with its reaction products and

$\infty$

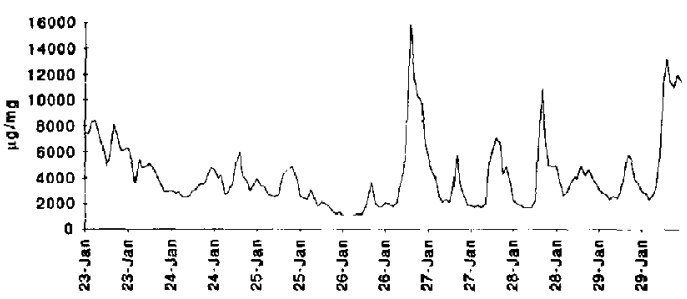

Figure 9. Carbon monoxide air concentration data of the "AGRATE" monitoring station from the Atmospheric Physics Department of the $4^{\circ}$ Unità Operativa Fisica e Tutela dell'Ambiente, Presidio Multizonale Igiene e Prevenzione di Milano, U.S.S.L. 75/III. Carbon monoxide air concentrations have a significant correlation with nonmethanic hydrocarbons levels. A relatively good agrecment in pollutant trend can be observed with benzene and toluene levels at the Mario Negri Institute especially for the data of January 27 and 29 , even if the sampling points were at sites a few kilometers apart. 
alters measurement accuracy. Because benzene is relatively nonreactive with normal air components, these phenomena are not expected and we did not observe any variations in the benzene- $d_{6}$ permeation rate due, for example, to changes in humidity, apart from cold trap clogging when the sample was too large.

The instrument described performed well in the short to medium period of continuous air monitoring. It was sensitive enough to measure benzene concentrations in urban air $24 \mathrm{~h}$ per day. A 10-pg benzene splitless injection gives a signal-to-noise ratio higher than 3 , so if we assume $100 \%$ adsorption and desorption efficiency of the trap, the lowest detection limit under the same experimental setup could be as low as $0.1 \mu \mathrm{g} / \mathrm{m}^{3}$. Determination of the ultimate sensitivity of this particular hardware goes beyond the scope of this study. Here the goal is to propose a new approach in air sampling. This approach was devised and dedicated exclusively to mass spectrometry detection because of the need for an isotopically labeled internal standard. Clearly a more sensitive mass spectrometer would perform better than this, but it is interesting to note that a "low end" mass spectrometer like the RGA might be useful in analytical chemistry, at least to solve some real everyday problems like the problem considered here. In cases like this, when the technical performance is adequate, it is preferable to use an RGA instead of a conventional organic mass spectrometer because it costs less and because its general mechanical simplicity makes it more reliable.

The 130-u mass range covers, for example, the molecular weight of 28 of the 32 compounds listed in EPA Method 1624: Volatile Organic Compounds by Isotopic Dilution GCMS. In theory all these compounds are measurable with this instrument provided the cold trap is capable of trapping them. Maintenance is reduced to a minimum: we never had to clean the source or the ion optics throughout this study.

We are now working to miniaturize all the different parts of the instrument, and future goals are directed toward long-term environmental air monitoring with this instrument in an automated monitoring station.

As a final consideration this analytical approach might be a candidate reference method for monitoring volatile organic compounds. The on-line isotopic dilution takes account of the possible sample losses during the concentration step and the GC/MS system gives the high specificity and sensitivity necessary for environmental air monitoring.

\section{Acknowledgments}

This study was supported by the CNR-ENEL, project interactions of energy system with human health and environment, Rome, Italy. The authors thank RIAL Vacuum S.p.A. for providing the RGA and technical assistance, and DANI S.p.A. for providing the gas chromatograph. The results of this study were presented in part at the 40th ASMS Conference on Mass Spectrometry and Allied Topics, Washington, DC, 1992, and at the 41st ASMS Conference on Mass Spectrometry and Allied Topics, San Francisco, CA, 1993.

\section{References}

1. Lioy, P. L. Environ. Sci. Technal. 1990, 24, 938-990.

2. Lave, B. L. Scicnce 1987, 23, 291-295.

3. Seinfeld, J. H. Science 1989, 243, 745-752.

4. Russel, M.; Gruber, M. Science 1987, 23, 286-290.

5. Fuselli, S.; Lanternari, S.; Proietto, R. A. Proceedings of the Ninth International Symposium on Capillary Chromatography: 1991; $\mathrm{PP}$ 414E-425E.

6. Sandmeyer, E. E. In Patty's Industrial Hygiene and Toxicology; Clayton, G. D.; Clayton, F. E., Eds.; Wiley: New York, 1981; pp 3253-3431.

7. Heavner, D. L.; Ogden, M. W.; Nelson, P. R. Environ. Sci. Technol. 1992, 26, 1731-1746

8. Gholson, A. R.; Jayanty, R. K. M.; Storm J. F. Anal. Chem. $1990,62,1899-1902$.

9. Chan, C. C.; Ozkaynak, H.; Spengler, J. D.; Sheldon, L. Enziron. Sci. Technol. 1991, 25, 964-972.

10. Hsu, J. P.; Miller, G.; Moran, V., III J. Chromatogr. Sci. 1991, $29,83-88$.

11. Tha, Q.; Oppenheimer, J. R; Weisel, C. P. Proceedings of the 38th ASMS Conference; 1990; pp 617-618.

12. Michael, L. C; Pellizzari, E.; Perritt, R. L.; Hartwell, T. D.; Westerdahl, D.; Nelson, W. C. Entiron, Sci. Technol. 1990, 24, 996-1003.

13. Bayer, C. W.; Black, M. S. J. Chromatogr. Sci, 1987, 25, 60-64.

14. Mcluckey, S. A.; Glish, G. L.; Asano, K. G.; Grant, B. C. Anal. Chem. 1988, 60, 2220-2227.

15. Dearth, M. A.; Glerczak, C. A.; Slegi, W. O. Environ, Sci. Technol. 1992, 26, 1573-1580.

16. Schoene, K.; Steinhenses, J; Fresenius, J. Anal Chem. 1990, $336,114-119$.

17. Comes, P.; Gonzales-Flesca, N.; Menard, T.; Grimalt, J. O. Anal. Chem. 1993, 65, 1048-1053.

18. Davoli, E,; Rossi, O, Fanelli, R. J. High Resolution Chromatogr. 1993, 16, 626-628.

19. Schoeller, D. A. J. Clin. Pharmacol, 1986, 396-399.

20. IARC Monograph, Supplement 7, 1987; pp 120-122.

21. Donald, J. M.; Hooper, K.; Hopenhayn-Rich, C. Environ. Sci. Technol. 1991, 237-244.

22. Dasch, J. M.; Williams, R. L. Environ. Sci. Technol. 1991, 25. 853-857.

23. U.S. EPA; Motor Vehicle-Related Air Toxics Study, Public Review Draft, 1992; pp. 5-17.

24. Wallace, L. A. Environ. Health Persp. 1989, 82, 165-169.

25. U.S. EPA. Motor Vehicle-Related Air Toxics Study. Public Review Draft, 1992 ; pp 5-9.

26. Teknivent Corp. NBS/Wiley Mass Spectral Database; 1987.

27. Lucero, D. P. Anal. Chem. 1971, 43, 1744-1749.

28. O'Keeffe, A. E.; Ortman, G. C. Anal. Chem. 1966, 6, 760-763.

29. Davoli, E; Cappellini, L.; Ferrari, S.; Fanelli, R. Proceedings of the 40th ASMS Conference on Mass Spectrometry and Allied Topics; Washington, DC, May 1992; pp 695-696.

30. Davoli, E.; Rossi, O.; Delprato, U.; Fanelli, R. Presented at the 41st ASMS Conference on Mass Spectrometry and Allied Topics; San Francisco, CA, May 1993.

31. Inghram, M. G.; Hayden, J, R. 1954, In Handbook on Mass Spectrometry. Nuclear Series; Report 14T; NRC:USA. 